\title{
Repurposing Typical Institutional Hall As Temporary Covid- 19 Quarantine Stations In Johor: A Review Study In KKTM
}

\author{
Nur Amalina Hanapi ${ }^{1 *}$, Nur Atikah Hanapi \\ ${ }^{1}$ Department of Architecture, Faculty of Civil Engineering and Built Environment, \\ Universiti Tun Hussein Onn Malaysia, 86400 Parit Raja, Batu Pahat, Johor, MALAYSIA \\ *Corresponding Author
}

DOI: https://doi.org/10.30880/ijie.2021.13.03.029

Received 05 January 2021; Accepted 13 May 2021; Available online 10 June 2021

\begin{abstract}
The current situation of the world with the pandemic of COVID 19 has brought a mass conversion of places as a temporary shelter recently. In Malaysia, the list of gazetted sites by the government for the COVID quarantine stations were being retrieved in March 2020 to facilitate Ministry of Health in coping with the sporadic diseases. To achieve lower production cost and rapid execution of disaster shelter for the pandemic, possible open plan spaces in institutional building will be identified to perform temporary medical shelter. Resuscitation area, wards, pharmacy, $\mathrm{x}$-ray room, staff room and meeting rooms are among the required spaces in determining the medical layout planning of the particular quarantine station. A descriptive and qualitative design was being used based on the literature review and case studies in order to get the information and to identify clear demarcation of circulation and movement in the quarantine station. Ultimately, foreseeing holistic changes and novel solutions in construction industry in Malaysia, this result will contribute to further assist authorities to gazette other institutional hall as transitional stay which will be become the norms nowadays.
\end{abstract}

Keywords: Design, adaptive reuse, quarantine station

\section{Introduction}

The mode and functions in daily life is rapidly changing due to the current pandemic. Thus, our buildings and infrastructures require some holistic changes and novel solutions that address the needs of living in post pandemic world [1]. Foreseeing the norms of future practice of the short term stay of quarantine, the conditions might depend on numerous arrangements of institutional buildings as the possible COVID19 quarantine stations due to the open plan assembly halls provided inside the building typology. Hence, architecture and medical planning layout experts are suggested to promote innovative designs of building layout that can cater people in isolation based on the adaptive reuse on typical intuitional hall with the minimum cost absorption as compared to building up new ones [2]. This information is anticipated to assist space planning layout template guideline with lower production cost and execute rapid implementation of disaster design shelter for architects and medical planners well equipped with better social distancing and accessibility.

\section{Literature Review}

\subsection{Packed and Constraint ICU CCU}

During the massive outbreak of COVID 19 in Malaysia, numerous hospitals is experiencing shortage of patients beds due to the increasing number of cases. Sungai Buloh Hospital was being functionally revamped to only equip 
treating and monitoring the pandemic cases. However, in anticipating unprecedented situations, the number of beds and wards will be insufficient to cope treating the disease if a sudden surge number of infected people happen in future [3]. Thus, relocating health care personnel and facilities were being strategized by the authorities in the recent Declaration of Quarantine Stations (No. 2) 2020 with the list of new gazetted quarantine stations declared which urges architecture background personnel to involve in mitigating the plan.

\subsection{Gazetted Sites for Quarantined Stations}

In exercise of the current practice of the post pandemic world, social distancing and isolation are becoming the norms in our lives [4]. Destination and movement of people including international border line, requires visitors to be quarantined for a short period of time before they may freely continue with the travel route [5]. Prior to that, Malaysia is aiming initial action of quarantine stations which is divided into various category intuitions and training academy to uphold and help monitoring the risen cases in future as per Declaration of Quarantine Stations (No. 2) 2020 under the Prevention and Control of Infectious Diseases Act 1988. These typologies of building were being chosen due the provision of open-spaces such as assembly hall which may accommodate the quarantine beds and structure in cubicles and tents. Among 409 of the new gazetted sites in Malaysia which include all sort of building typology and functions, approximately 50 of them were in Johor. After detail screening of the Johor gazetted sites, community colleges, training centre and national service camp are among the highest categories as per Fig. 1. Hence, this research will be identifying the ideal template for those assembly halls in the intuitional building in Johor that has been gazetted as the COVID19 quarantine stations

\subsection{Criteria of Medical Layout Planning of Quarantine Stations Premises}

Stringent procurement in developing the quarantine station shall be applied to ensure successful delegation especially on the space planning circulation and the procedure carried out in the stations [6]. In Malaysia, series of interactions and discussions have to be scheduled in every client consultant meeting to ensure synchronise understanding of the related spatial planning, medical planning layout and medical equipment items prior to Certificate of Completion and Compliance (CCC) and commencement of the hospital operation. Resuscitation area, wards, pharmacy, x-ray room, staff room and meeting rooms are among the essential services to uphold the COVID19 quarantine station [3]. Deliberating on the smooth movement of the dirty and clean flow inside the quarantine station are fundamental to sustain hygienic and sterile conditions in the quarantine zone and to restrict movement of infected person in order to stop the spread of SAR-CoV-2 [2]. Fig. 2 describes the medical planning layout drafted for the last SARS quarantine station which assemble profound segregations and flows to operate the centre. General pre-requisite requirement under the Guidelines COVID-19 Management No.5/2020 also gazetted premise for COVID19 quarantine shall be following the listed items below:

a) Allocation all PUI with single room provision.

b) Limited or constraint spaces should however to be distance at $1 \mathrm{~m}$ apart from each other.

c) Bathroom, ensuite or toilet provision in each room.

d) Medical preparation area which includes medication storage, consumable items, linen and PPE.

e) Clinical examination room.

\subsection{Compliance to the Standard Requirements}

Malaysian local government has established laws and legislations to ensure the proposed building complied to the safety and standard requirements listed [7]. There will be few government agencies and local authorises guidelines involved in gazetting the quarantine station as well to allow correct systems are being practiced [1]. In the initial interaction between the consultant team and the end users which are the medical personnel themselves, priority spaces and requirements are being identified to facilitate COVID19 case in comparison to other spaces that is considered none related to the pandemic as per last Fig. 3 descriptions on spaces.

Below are the general provisions outlined by Standards of Private Healthcare Facilities or Services in relation to setting a medical centre:

a) Location. Location of the quarantine station need to be allocated with hall or open plan area.

b) General Design Requirements. Structure or allocation like elevators, stairways, ramps and corridors will have to be segregated between clean and dirty area particularly quarantine stations. Entrance, Exits, Doors and Windows shall be fully guided based on sign and labels in addition to clean and dirty flow identification.

c) Accommodation for Patients. Room or ward requirement shall be both in width and length size minimum of $3.2 \mathrm{~m}$ in which the space allowance between beds shall also comply with minimum of $1.5 \mathrm{~m}$ (between beds) and $0.9 \mathrm{~m}$ from the wall to allow optimum movement. In terms of patients' room location, it should be accessible from corridor and a distance of maximum $24.4 \mathrm{~m}$ from nurse's station.

d) General Standards for Patient Room Facilities. This particular requirement shall apply the essential services and spaces to uphold the functions of the temporary quarantine building such as clean utility room, pantry or 
nourishment station, clinical examination and treatment room, linen room, soiled utility room, medication preparation area, nurses' station, lighting for patients' room, facilities for bathing, etc.

e) Waste Disposal. All the clinical, hazardous and disposal waste including those in kitchen and dining area shall be properly segregated and disposed in the designated refuse area [1].

f) Housekeeping. As part of necessities any medical facilities, this particular space has to be allocated to sustain and provide disinfect supplies and equipment with standard, schedules and written procedure carried out.

g) Linen and Laundry. To ensure daily hygiene to be practiced linen shall be replaced daily wise and this practice do require various dissociation area to isolate the infectious disease linen, linen for nursery, soiled linen sorting, laundry facilities and linen storage room equipped with well ventilation area to prevent recirculation of air in the room.

h) Communication and transport arrangements. Provision for all communication system including online data and transport arrangement to the gazette quarantine station shall be provided to allow smooth screening process for the patients.

i) Maintenance. Standard written policy and procedure from the procurement team shall be provided including supervision scheduling.

j) General Nursing and Personal Care Requirements. Provision for nursing staffing master plan including supervision scheduling, personal care, nurses' station in the radius of all patient's rooms with clear traffic compound especially those in the obstetric unit, surgical areas and treatment rooms.

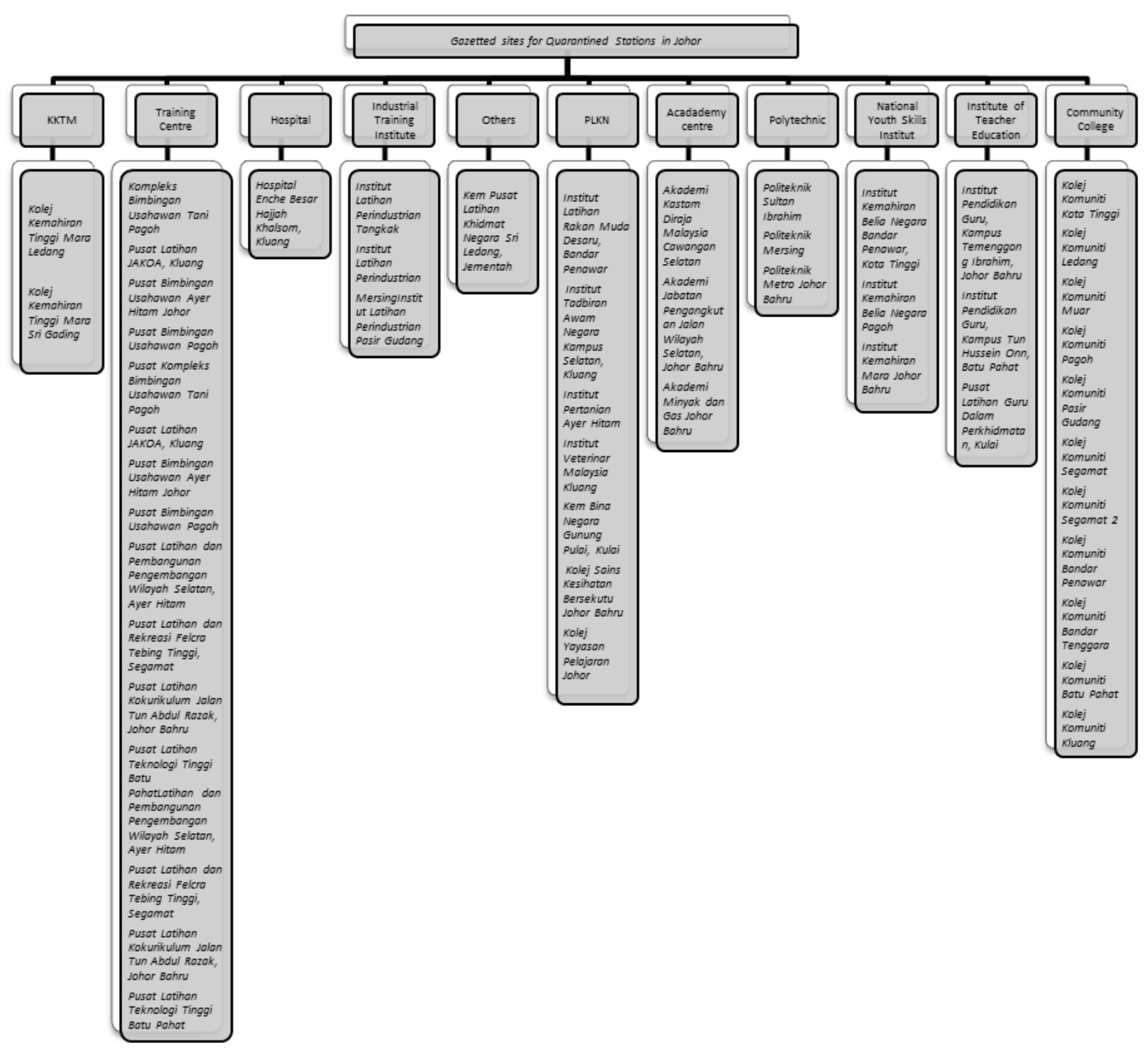

Fig. 1 - Classification of quarantine stations in Johor 

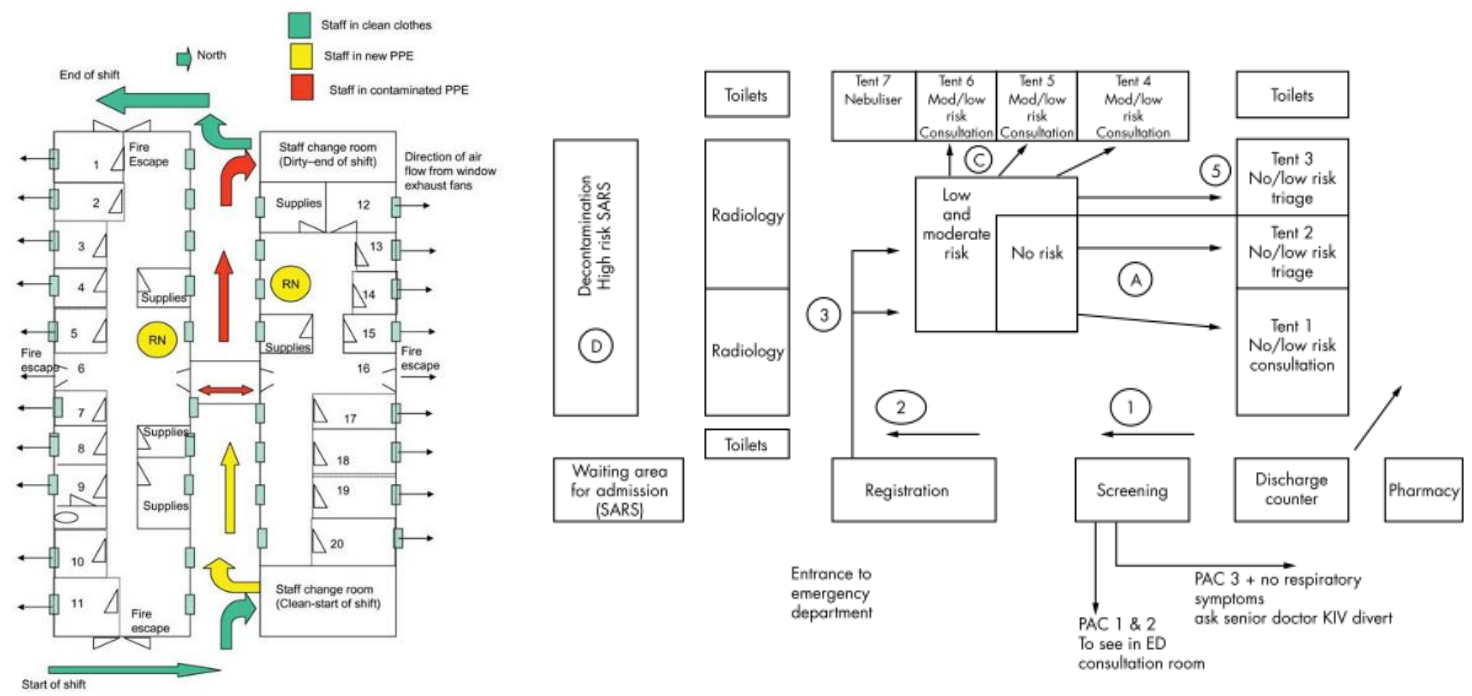

Fig. 2 - The space planning and flow configuration in the last SARS quarantine stations

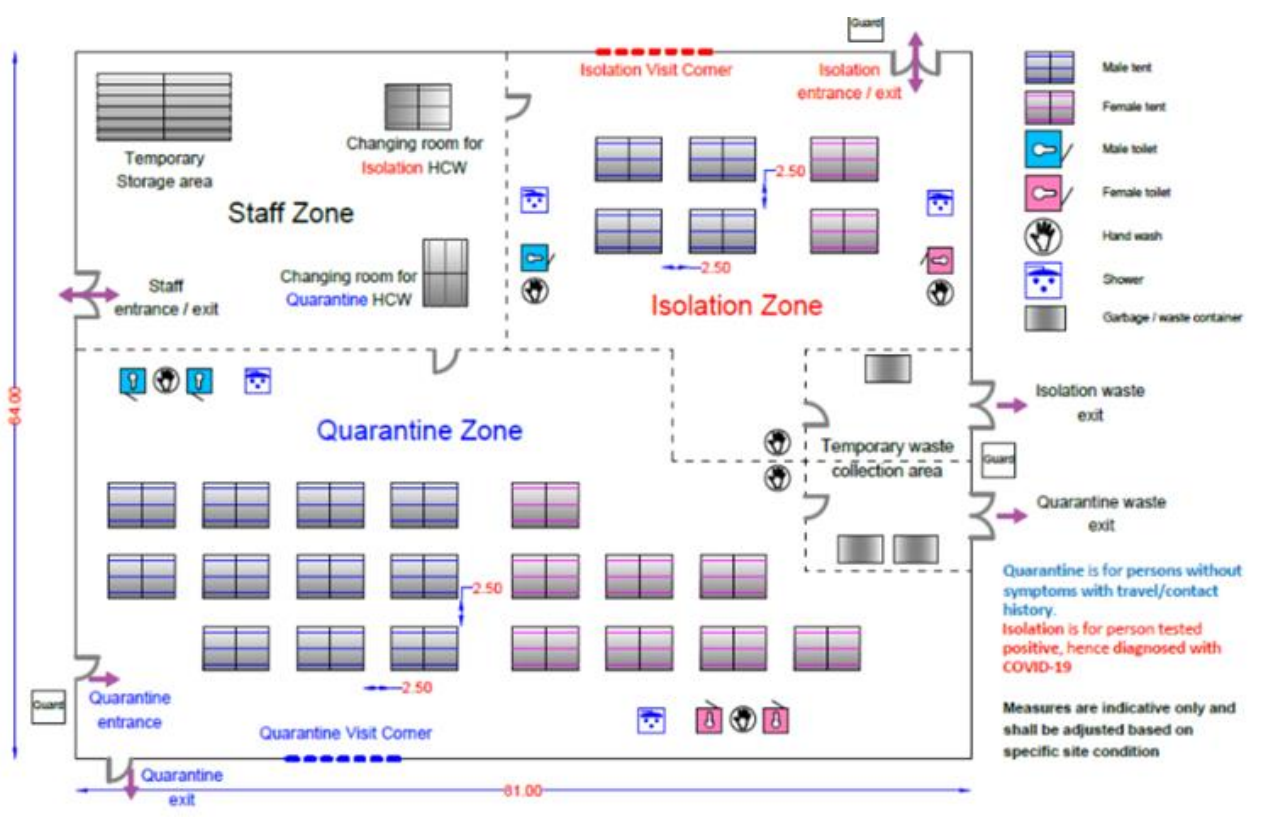

Fig. 3 - Proposed last quarantine and isolation area during SARS

\section{Methodology}

To complete this study, methods involved are observation at institution hall in Kolej Kemahiran Tinggi Mara (KKTM) Ledang as case study and literature reviews screening to identify the standard feasible design solutions for KKTM. This is a qualitative research with primary data type. Based on the evaluation and observation, proposed template layout will be injected and imparted in the adaptive reuse of assembly hall to ensure attainable scheme for repurposing institutional buildings is achievable. Due to the provision of open plan area and spacious hall, this research is targeted to achieve more economical design solutions for COVID19 quarantines station in terms of space planning to cater the priority areas like isolation room, quarantine zone, satellite laboratory, x-ray room and resuscitation area [8].

\section{Results and Discussions}

\subsection{Better Space Zoning Allocation and Social Distancing in The Open Plan Assembly Hall}

Based on the typical layout of a normal hall, significant and essentials spaces in treating the pandemic are likely attainable. Resuscitation area, wards, pharmacy, x-ray room, staff room and meeting rooms are among the most identified spaces in determining the quarantine station medical layout planning [3]. The picture below indication the 
proposed basic planning concept for the quarantine centre in which most of the common type of spaces and layout suggested may be used as the standard scheme for others.

a) Resuscitation area near to isolation. Location of the resuscitation area need to be allocated near to isolation ward in where emergency collapse happened to one of the patients, the bed can be directly move to the resuscitation area in where the immediate treatment will be given.

b) Isolation area. Isolation room should be put somewhere accessible to the nurses' station and resuscitation area since these are the people in where 24 hours surveillance need to be given.

c) Quarantine zone. Room or ward requirement for the patients shall be major anchor tenant for the quarantine station in terms of space planning.

d) Satellite Laboratory near to reception area. This particular requirement shall apply the other essential services like the swab test area, rapid test kit area and blood collection area to ease the flow circulation sequence for the patients receiving the screening processes.

e) Staff area near to isolation and quarantine area. To facilitate the procedure in terms of space planning the dedicated staff lounge and changing room for on-call nurses' and doctors shall be design near to their high stimulus working area.

Thus, the result template strongly suggests the zoning and spatial planning sample that can be used based on the quarantine station that has been erected for the last SARS pandemic previously. This part of discussion will focus on the basic standards of chosen assembly hall of gazetted sites in Johor, in particular, KKTM Ledang which may accommodate the space zoning template for quarantine station as per Fig. 5. The analysis below are provisions complied to Standards of Private Healthcare Facilities or Services:

a) Location. Location of the quarantine station need to be allocated with hall area. Most of the chosen gazette sites are adorned with in-house halls that can be used as the quarantine station and for this case the location of KKTM Ledang is within radius of Bukit Gambir, Tangkak.

b) General Design Requirements. Selected KKTM hall is well equipped with doors, windows, stairways, ramps.

c) Entrance and exit. These provisions can be fully guided based on the future clean and dirty flow design in the quarantine design.

d) Accommodation for Patients. With the designated sport courts in the buildings, it is anticipated to monitor minimum of 128 patients at one time.

e) General Standards for Patient Room Facilities. Patients room are designate to accommodate clustered planning with the clear minimum bed-to-bed of $2 \mathrm{~m}$.

f) Waste disposal. In compliance to the local authority regulations, the waste disposal is being regulated by Majlis Daerah Tangkak.

g) Housekeeping. The existing provision of the janitor closet near the assembly hall area to allow day-to-day cleaning service routine to be operated.

h) Linen and Laundry. Linen storage and line racks are laced in island clustered near to nurses' station to facilitated the procedure and internal movement in the quarantine station.

i) Communication and transport arrangements. Communication system, Transport arrangements

j) Maintenance. Written policy, procedure or supervision management shall be enlisted by the District Health Office.

k) General Nursing and Personal Care Requirements. The nurse's counters and the medical preparation areas are to be designed as an island in the quarantine zone to allow vast and broad surveillance system on the patients.

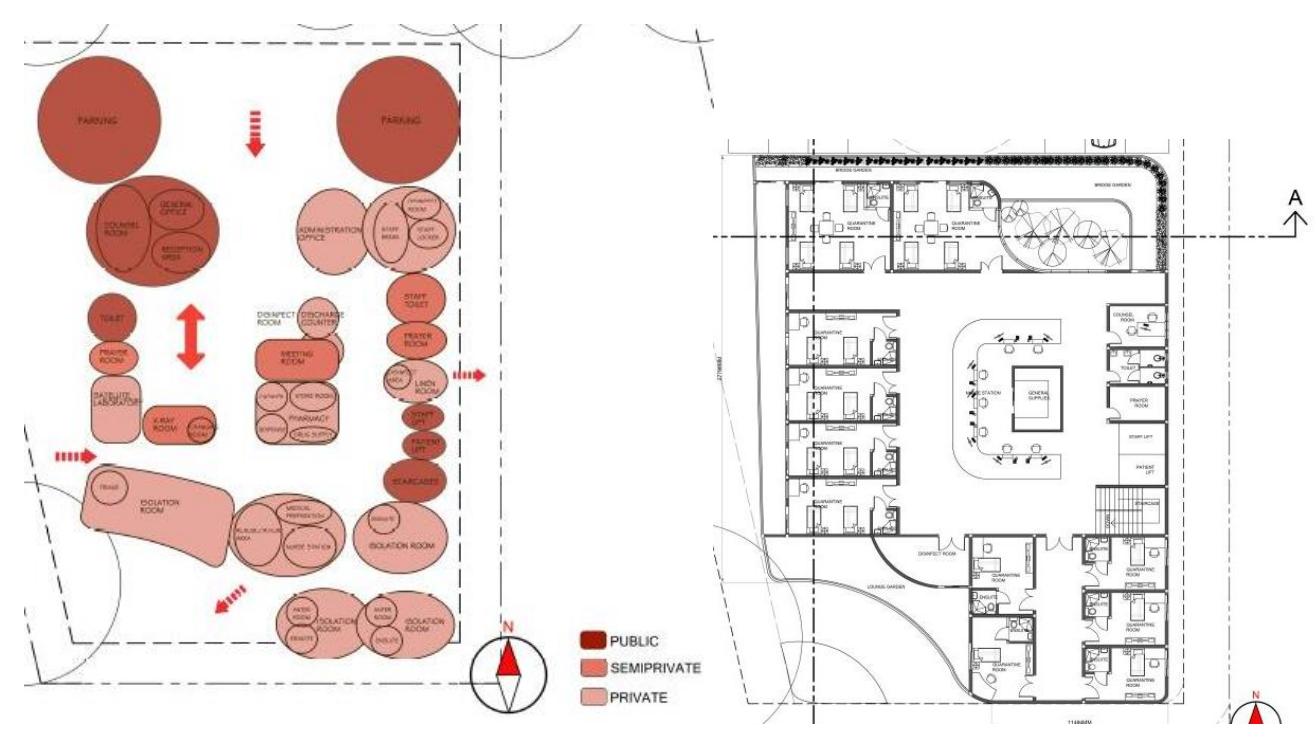



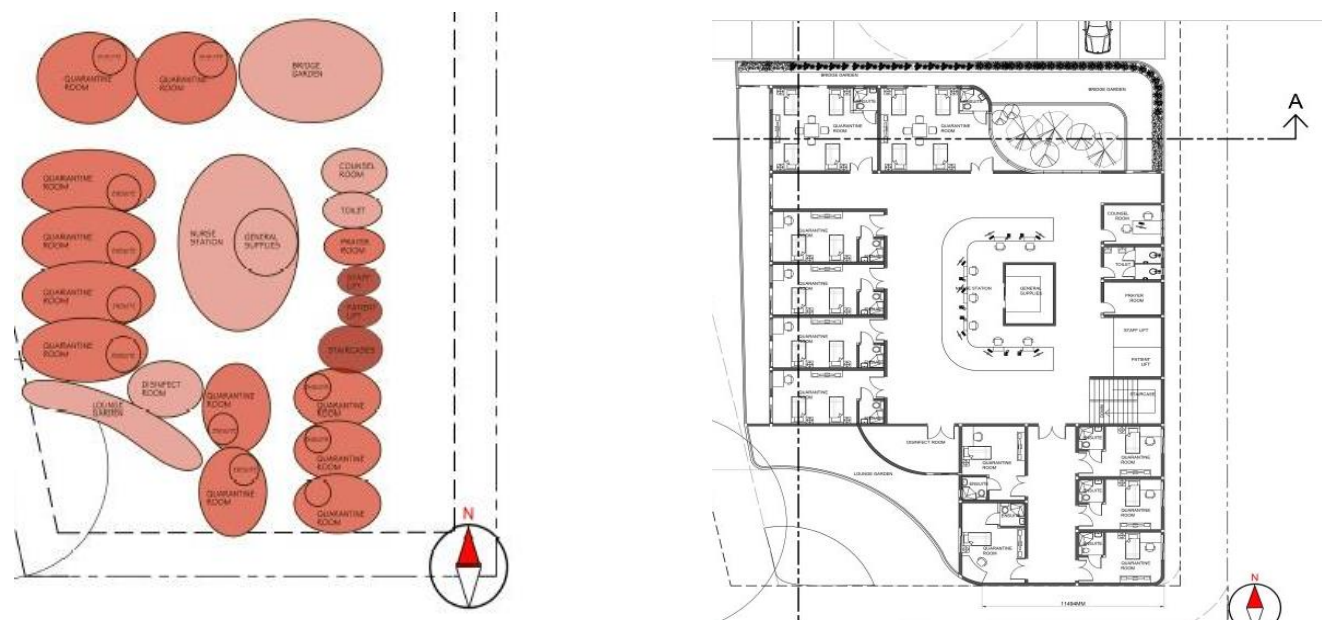

Fig. 4 - Proposed space planning example in Covid19 quarantine station by Che Winni
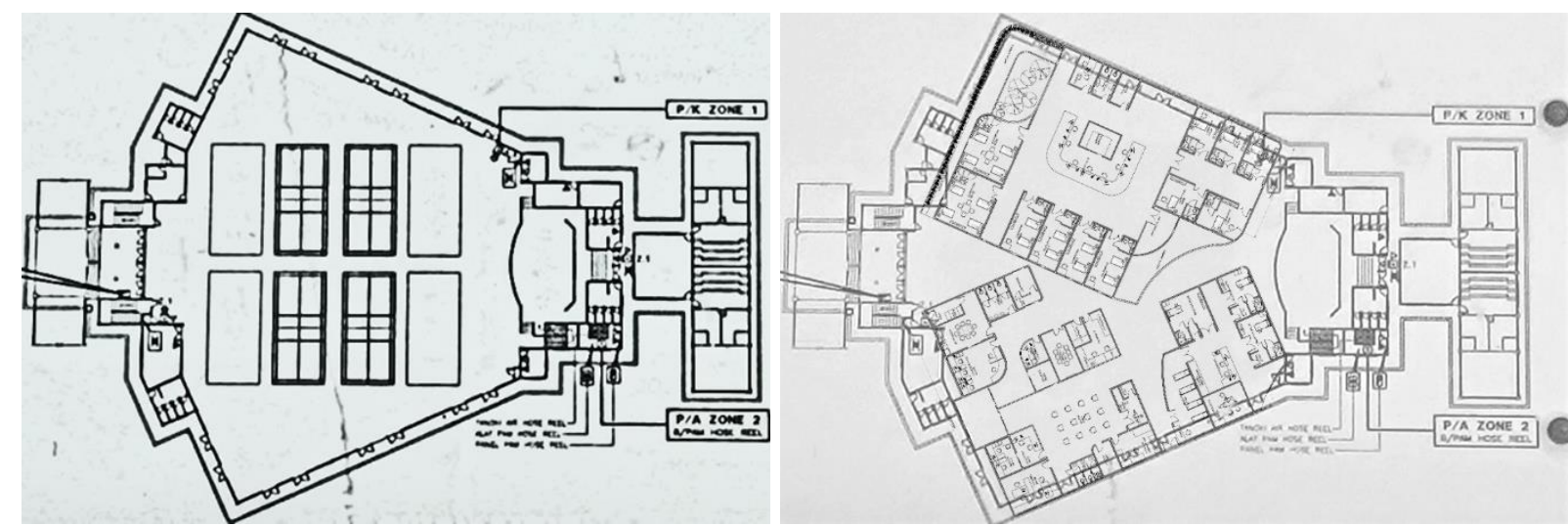

Fig. 5 - KKTM Ledang one new of the gazetted sites for quarantine station in Johor

\subsection{Better Accessibility and Circulation for Clean and Dirty Flow in The Quarantine Station}

All medical equipment should be handled in good working order and any reusable tools must be cleaned and sterilized accordingly to the manufacturer's descriptions [4]. Removal of linen, replenishing stock of fresh linen, removal of waste and replacement of waste containers were among the tasks to be conducted on quarantine station. Hence, providing clear routes in any medical treatment shelter is a must to ensure sufficient allowance of decontamination process follow specific practice in the quarantine zone are being regularly observed [9]. The red will demarcate the dirty flow and the blue will indicate the proposed clean flow for the proposal template in the quarantine zone stations for institutional building. Those demarcation line will prevent the flow or processes conducted to be crisscrossed and provide more clarity in space designing.

\subsection{Better Travel Distance and Amenities Provisions for Localized Non-Hospital Quarantine Centre}

Due to the sporadic disease which has to be quickly identified, having a quarantine station nearby the vicinity will be the best solution in coping the pandemic [3]. Reducing the waiting time by providing more localised quarantine stations apart from depending on multiple agencies like Malaysian Royal Police, Local Council or District Health Office, can help mitigating reducing the rate of infection. Location of the Muar Community College for example could cater more residents in the sub-urban areas as compared for them to travel to Muar Health District Office in the city area. To put into detail perspective lots of amenities and services have been provided between the radius of the list of gazetted quarantine stations [7]. Below is list of responsibilities highlighted to alleviate the COVID19 cases and the cooperation bodies involved in advocating the services.

a) General Cleanliness. The local authorities will be subjected to the general cleanliness of the premises.

b) Clinical waste. District Health Office shall be responsible for the disposable of clinical items used for the quarantine station. 
c) General waste. As per general cleanliness category the general waste shall be accountable to the scope of work of the local authorities.

d) Food. Meal allocation shall be regularly organized and regulated Ministry of by Ministry of Women, Family and Community Development at the national level with the aid District Health Officer.

e) Water Supply. Provision of the resource shall be provided by the Public Work Department (JKR).

f) Security. Depending on the situations and necessity gazetted quarantine sites shall be monitored by PDRM or RELA to refrain and oversee the PUI.

g) Linen. Extension service from the hospital shall be conducted the same concession party in outsourcing the clean linen service.

h) Clinical Management of Person in Quarantine Centre. Administration of the patient in the quarantine station shall be under discretion of the District Health Officers.
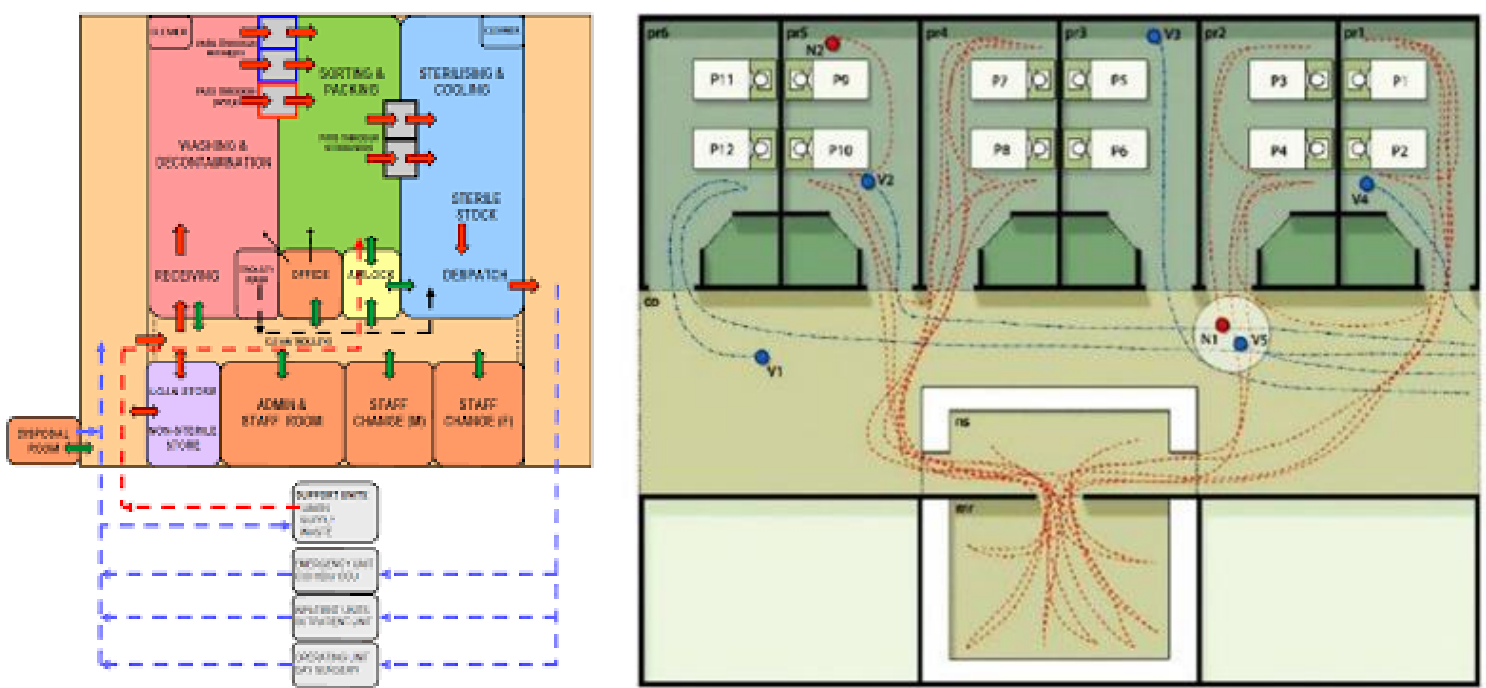

Fig. 6 - Patient Circulation. Collection and disposal of general waste is the responsibility of Local Council

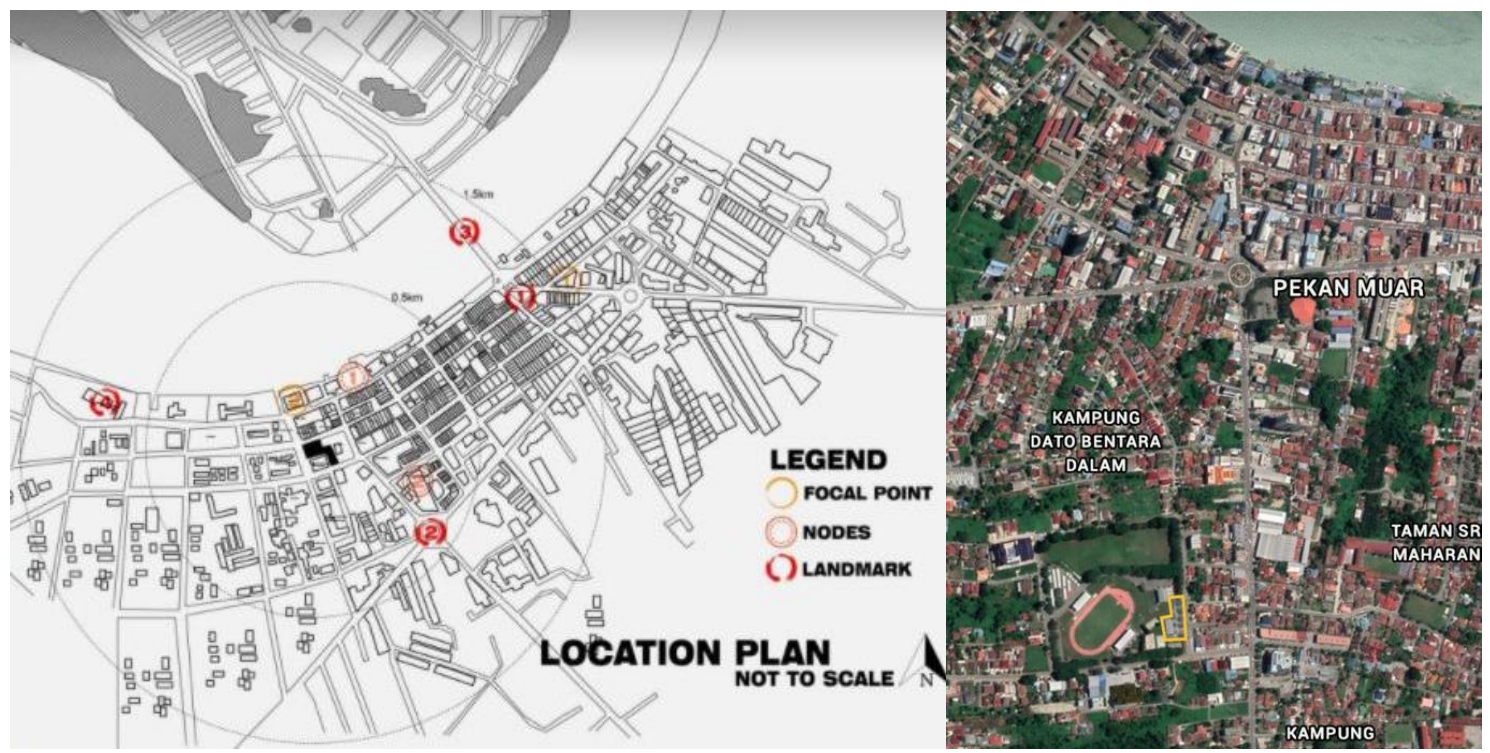

Fig. 7 - Location of Muar Community College

\subsection{Lower Cost Production by The Adaptive Reuse Building}

The implementation of the adaptive reuse on the existing institutional building has proven that cost incurred for the building construction material such as steel, concrete, brick or timber being cut omitted [10]. This has allowed rapid execution of the shelters itself by focusing only space planning and querying on medical equipment and furnishing items needed. Spacious area like assembly hall enables tent or cubicle structure to be infilled in sick bay areas for the quarantined persons [2]. The basic attainments in terms of procedure in the normal medical planning building as per 
Fig. 8 below thus shorten the period as opposed to constructing new ones which compelled with numerous tedious preparations including documentations procedures.

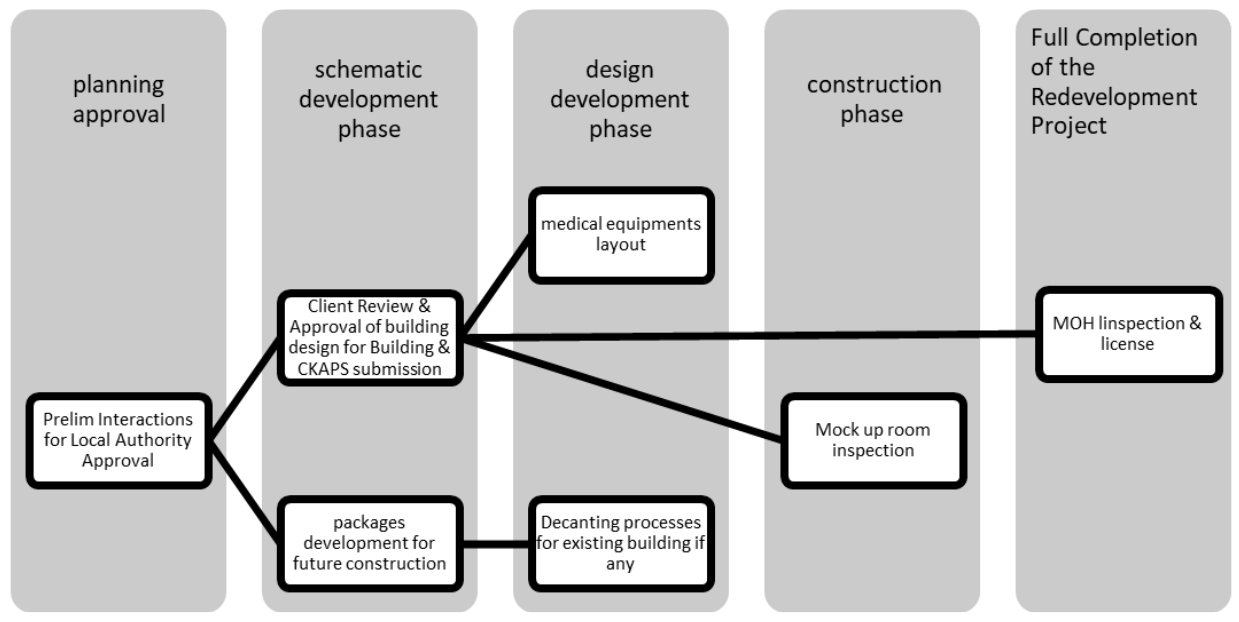

Fig. 8 - Scope of mandatory construction phases

\section{Results and Discussions}

In general, it is being recommended that the basic template of space zoning and its compliance to the health act are possible to be done to other institutional buildings that contain open plan assembly hall as an adaptive reuse project implementation. With respect to the local guideline given as well, this research has also deliberated the initial scheme layout for the rural area to prepare for the essential need and spaces to be converted to other quarantine station.

\section{Acknowledgment}

The authors would like to thank the Department of Architecture, Faculty of Civil Engineering and Built Environment, Universiti Tun Hussein Onn Malaysia, Parit Raja, Batu Pahat, Johor.

\section{References}

[1] Ilyas S., Ranjan R. \& Kim H. (2020). Science of the total environment disinfection technology and strategies for COVID-19 hospital and bio-medical waste management. Science of the Total Environment, 749, 141652

[2] Jamali N., Leung R. K. \& Verderber S. (2020). A review of computerized hospital layout modelling techniques and their ethical implications. Frontiers of Architectural Research, 9, 498-513

[3] Goh Y., Chua W., Lee J. K. T., Ang B. W. L., Liang C. R., Tan C. A., Choong D. A. W., Hoon H. X., Ong M. K. L. \& Quek S. T. (2020). Operational strategies to prevent coronavirus disease 2019 (COVID-19) spread in radiology: Experience from a Singapore Radiology Department after severe acute respiratory syndrome. Journal of the American College of Radiology., 17. 717-723

[4] Bleibtreu A., Bertine M., Bertin C., Houhou-fidouh N. \& Visseaux B. (2020). Focus on Middle East respiratory syndrome coronavirus (MERS-CoV) Le point sur le MERS-Cov. Mẻdecine et Maladies Infectieuses, 50. 243-251

[5] Blendon R. J., DesRoches C. M., Cetron M. S., Benson J. M., Meinhardt T. \& Pollard W. (2006). Attitudes toward the use of quarantine in a public health emergency in four countries. Health Affairs, 25, 215-25

[6] Chen D., Song F., Tang L., Zhang H., Shao J., Qiu R. \& Wang X. (2020). Quarantine experience of close contacts of COVID-19 patients in China: A qualitative descriptive study. General Hospital Psychiatry, 66, 81-88

[7] Jiang S. \& Nee A. Y. C. (2013). A novel facility layout planning and optimization methodology. CIRP Annals, 62, 483-486

[8] Ilyas S., Ranjan R. \& Kim H. (2020). Science of the total environment disinfection technology and strategies for COVID-19 hospital and bio-medical waste management. Science of the Total Environment, 749, 141652

[9] Cirulis A. \& Brigmanis K. B. (2013). 3D outdoor augmented reality for architecture and urban planning. Procedia Computer Science, 25, 71-79

[10] International Law Book Services (2013). Uniform Building By-Laws 1984 International Law Book Services, pp 58-105 